\title{
O intervalo Escola-Universidade: mais do que uma questão genérica
}

\author{
Cristina Becker Lopes Perna* \\ Lucas Zambrano Rollsing** \\ Rafael Padilha Ferreira***
}

\begin{abstract}
Resumo
O presente artigo almeja trazer à agenda das discussões sobre letramento na universidade a lacuna existente entre o ensino e a aprendizagem de gêneros escolares e de gêneros acadêmicos. Nossa inquietação é fruto de uma preocupação com os alunos ingressantes em instituições de ensino superior que não tiveram uma experiência escolar com vistas a uma prática social de letramento acadêmico. A partir do tema proposto, refletimos sobre como a teoria dos gêneros discursivos de Bakhtin, bem como sua aplicabilidade, auxilia no desenvolvimento do letramento acadêmico desses alunos universitários. A proficiência, ou inserção, na esfera discursiva acadêmica está muito relacionada com a competência genérica que o aluno deve possuir para assegurar sua comunicação, de forma a alcançar seu status de sujeito discursivo e transformador. Portanto, defendemos que, aliada à teoria de gêneros discursivos, a metodologia de ensino de Português para Fins Acadêmicos, nos moldes da consagrada área de Inglês para Fins Acadêmicos (English for Academic Purposes), pode, em muito, contribuir para se criar uma tradição de letramento acadêmico que propicie ao estudante uma experiência mais significativa não somente na sua esfera acadêmica, mas também no domínio discursivo do qual ele venha a participar, uma vez egresso da universidade e apto para atuar na sua profissão.

Palavras-chave: Teoria dos gêneros discursivos. Competência genérica. Letramento acadêmico. Português para fins acadêmicos.
\end{abstract}

Recebido em: 29/04/2017

Aceito em: 09/12/2017

* Doutora em Linguística, Professora Adjunta do Programa de Pós-Graduação em Letras da Escola de Humanidades da Pontifícia Universidade Católica do Rio Grande do Sul.

** Mestrando em Linguística do Programa de Pós-Graduação em Letras da Escola de Humanidades da Pontifícia Universidade Católica do Rio Grande do Sul. Bolsista CAPES.

*** Mestrando em Linguística do Programa de Pós-Graduação em Letras da Escola de Humanidades da Pontifícia Universidade Católica do Rio Grande do Sul. Bolsista CNPq. 


\section{Considerações iniciais}

O Brasil está passando por uma profunda transformação educacional no ensino médio (Novo Ensino Médio). ${ }^{1}$ Essa proposta se tornou muito presente nas discussões educacionais ao longo do país nos últimos meses e nos leva a questionar modelos de ensino em voga que, de certa forma, caracterizam a educação brasileira no atual contexto sócio histórico. Exemplos desses modelos são escolas públicas profissionalizantes, de ensino politécnico ou técnico direcionadas em seu projeto político-pedagógico para dois fins: (i) preparar seus alunos para exercerem atividades acadêmicas como, por exemplo, a escrita de trabalhos de conclusão de curso e de artigos; (ii) formar mão-de-obra especializada. Algumas instituições exigem de seus alunos trabalhos de conclusão de curso nos moldes dos gêneros encontrados no ensino superior, tais como monografias, relatórios de pesquisa ou artigos científicos. Porém, essa caracterização escolar que proporciona uma experiência de produção de gêneros acadêmicos ao seu aluno parece estar longe de ser a realidade do ensino em escala nacional.

O presente artigo almeja trazer à agenda das discussões sobre letramento na universidade, sem vistas a uma conclusão, o intervalo existente entre o ensino e a aprendizagem de gêneros escolares e de gêneros acadêmicos. Nossa inquietação é fruto de uma preocupação com os alunos ingressantes em instituições de ensino superior que não tiveram uma experiência escolar voltada para uma prática de letramento social e, nesse caso, acadêmico.

A partir do tema proposto, refletiremos sobre como a teoria dos gêneros discursivos de Bakhtin e seu círculo, bem como sua aplicabilidade, auxilia no desenvolvimento do letramento acadêmico desses alunos universitários. A proficiência, ou inserção, na esfera discursiva acadêmica está muito relacionada com a competência genérica que o aluno deve aprimorar para assegurar sua comunicação, de forma a alcançar seu status de sujeito discursivo e transformador, pois, conforme Maingueneau bem ilustra "[..] sendo partilhada pelos membros de uma coletividade, a competência genérica permite também evitar a violência, o mal-entendido, a angústia de um ou outro dos participantes da troca verbal [...], enfim, ela permite assegurar a comunicação verbal." (MAINGUENEAU, 2013, p. 70).

1 Mais detalhes disponíveis em: http://portal.mec.gov.br/component/content/article?id=40361. 
Logo, podemos propor uma justificativa ao mal-entendido comunicativo referido por Maingueneau: os alunos de ensino médio estão habituados à sua esfera discursiva escolar, a qual seleciona (possibilita) determinados gêneros discursivos, tais como a redação de vestibular/ENEM, a notícia de jornal, a crônica, o conto, o livro didático etc., aos quais são durante anos expostos, seja para a sua produção, seja para o seu consumo. Esses gêneros escolares se diferenciam amplamente daqueles que estabilizam as atividades do ensino superior. Existe uma miríade de elementos comunicativos que um enunciador escolar e um enunciador universitário, em seus discursos, detêm (ou pelo menos deveriam deter) para legitimar suas ações no ambiente social de que participam.

$\mathrm{O}$ meio acadêmico, mais propriamente o ensino superior $[\ldots]$ apresenta muitas particularidades que o distinguem de outros, como o ensino fundamental e o médio. Em virtude de práticas de letramento que são próprias do meio acadêmico, muitos alunos podem se sentir distantes, inicialmente, de propostas advindas de professores, por não dominarem as linguagens sociais recorrentes nesse meio. (FISCHER, 2008, p. 179)

Com essa citação em mente, levantamos o seguinte questionamento: como um aluno egresso do ensino médio regular se empodera desses elementos discursivos da esfera acadêmica para atuar, via gêneros (orais e escritos), na sua nova esfera discursiva? Tal questionamento é um dos levantados nas discussões, assim como um dos objetivos, do Grupo de Pesquisa sobre o Uso e Processamento de Língua Adicional (UPLA), da Escola de Humanidades da Pontifícia Universidade Católica do Rio Grande do Sul. ${ }^{2}$ O UPLA se centra em questões referentes ao ensino, à aprendizagem e ao uso da língua portuguesa dentro da esfera discursiva acadêmica por alunos nativos e não nativos. Este trabalho, portanto, almeja também propor uma reflexão teórica a ser ainda implementada em um contexto escolar/acadêmico real.

Na seção seguinte, trazemos os modelos teóricos que embasam a epistemologia do grupo, a presente discussão, e as pesquisas oriundas da área da Linguística Aplicada, para o ensino de línguas para fins específicos e, por extensão, para fins acadêmicos.

2 Espelho do grupo: dgp.cnpq.br/dgp/espelhogrupo/0705653235733182. 


\section{Português para fins acadêmicos (PFA)}

A área de estudos focada no ensino especializado de línguas teve impulso na década de 1970. A partir daí, houve muitos desdobramentos e pesquisas que puderam assentar essa linha de estudos e conferir a ela um status de relevância no contexto acadêmico. Em inglês, tal área tomou forma sob a denominação de English for Specific Purposes (Inglês para Fins Específicos), cuja extensão ou especificação postulou o English for Academic Purposes (Inglês para Fins Acadêmicos), doravante EAP. A produção de materiais de ensino de inglês como língua estrangeira com foco nas habilidades de estudo (study skills) tornou-se muito comum tanto nos EUA quanto na Inglaterra, e uma grande discussão acerca das definições desses temas se iniciou (JORDAN, 1997). ${ }^{3}$ De acordo com Jordan (1997) e com Hyland (2006), os pesquisadores e professores de inglês como língua estrangeira na academia notaram que, dentre outros fatores, a criação de programas de intercâmbio acadêmico entre os países da Europa necessitava de mais atenção. Passou a haver uma maior circulação de estudantes falantes de outras línguas em instituições de ensino superior, e esses estudantes precisavam ler e produzir textos acadêmicos em língua inglesa, ou seja, produzir e consumir gêneros da esfera acadêmica; contudo, muitas vezes fracassavam nessas atividades, por questões de diferenças culturais e como essas diferentes culturas concebiam e estabilizavam os seus gêneros.

Com as preocupações acerca do ensino de EAP, pesquisadores da área passaram a levantar outros questionamentos, tais como: esse ensino deve ser "geral" ou voltado para as especificidades de cada área do conhecimento? Professores de língua estão preparados para lidar com questões técnicas de cada área? Professores especialistas em suas áreas têm formação linguística para orientar seus alunos sobre questões de EAP? As habilidades de estudo não são suficientes para oferecer aos alunos orientações sobre como proceder na escritura de textos da esfera acadêmica? Tais questões não são fáceis de responder, o que é comprovado pela ampla gama de estudos dedicados a eles (JORDAN, 1997; FLOWERDEW; PEACOCK, 2001; HYLAND, 2006).

Com um percurso de mais de quarenta anos, os estudos de EAP atualmente são embasados por teorias de educação linguística calcadas em pesquisas, o que

3 Para um estudo mais aprofundado sobre o conceito de study skills, ver Jordan (1997). 
coloca o tópico como o carro chefe no desenvolvimento de práticas de ensino inovadoras (HYLAND, 2006). Essa evolução, contudo, fez os estudiosos desviarem o foco de sua atenção da conceituação de EAP para, mais recentemente, a questão da existência ou não de características e de formas de comunicação específicas de cada disciplina / área do conhecimento. Citando Hyland mais uma vez, o autor afirma "[...] há evidências convincentes no espectro acadêmico de que as disciplinas apresentam características e formas distintas de comunicação que os estudantes precisam aprender a dominar para serem bem-sucedidos." (HYLAND, 2006, p. 3, tradução nossa).

$\mathrm{Na}$ figura abaixo, reproduzimos o esquema trazido por Jordan (1997), a fim de demonstrar como se dá essa especialização do ensino, de acordo com o uso esperado que irá se fazer da língua, neste caso, a língua inglesa.

Figura 1 - Objetivos/Fins para o Ensino de Língua Inglesa.

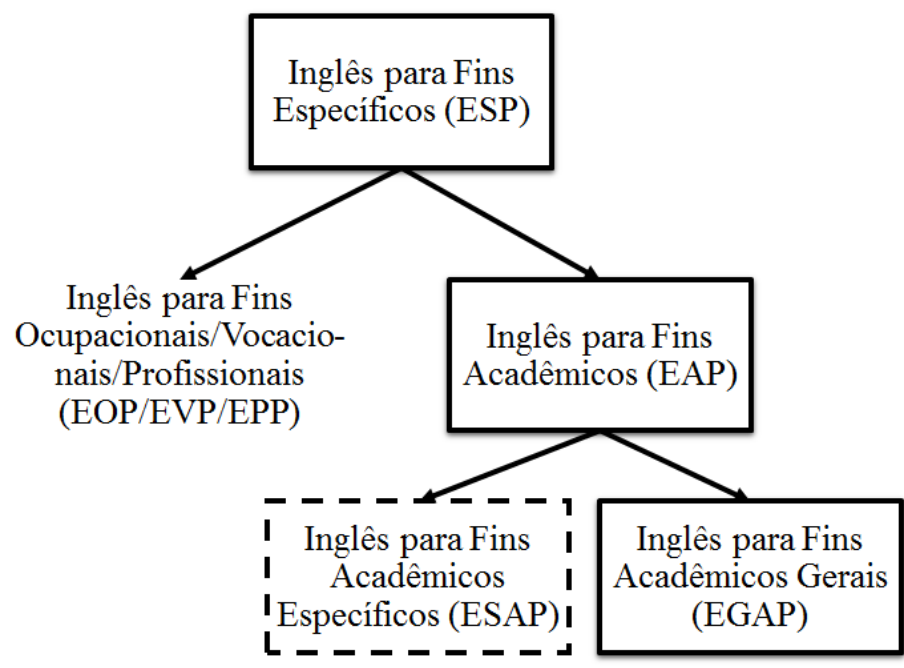

Fonte: Traduzido e adaptado de Jordan (1997, p. 3).

Conforme podemos depreender do esquema acima, o que retoma o dito anteriormente sobre as especificidades de ensino de EAP (seja ESAP, seja EGAP), a língua é utilizada de acordo com o objetivo que seus falantes buscam alcançar, os quais estão localizados em uma dada esfera discursiva que molda seu estilo, tanto oral quanto escrito, o que acaba por caracterizar os gêneros ali encontrados e ali forjados. Bakhtin claramente afirma "[..] onde há estilo há gênero. A passagem do 
estilo de um gênero para outro não só modifica o caráter do estilo nas condições do gênero que não lhe é próprio como também destrói ou renova tal gênero." (BAKHTIN, 2016, p. 21). Essa visão bakhtiniana também postula, de certa forma, que a língua está por trás de qualquer atividade humana, ou seja, a esfera discursiva e a língua são inextricavelmente companheiras no curso da enunciação.

Essa noção nos é muito valiosa para entender o funcionamento da linguagem enquanto forma de agir sobre o mundo e de constituir a própria visão do que vem a ser a realidade. Por isso, na seção seguinte, exploraremos os conceitos postulados por Bakhtin, Maingueneau e Marcuschi, os quais formam o sustentáculo da análise a que nos propomos neste trabalho. Com isso em mente, nós, assim como o grupo UPLA, procuramos orientar o PFA nessa perspectiva pragmática e discursiva da língua.

Para tal, o PFA é analisado através da forma como é usado por alunos de graduação e pós-graduação na PUCRS. Procede-se através de coleta e análise de dados de corpora escrito e oral - processo que tem permitido o desenvolvimento de pesquisas em português acadêmico pelo UPLA, entre elas a descrição do sistema pronominal em Português Brasileiro (PB) (MOLSING; PERNA, no prelo), de adjetivos (MORO, 2014), de sintagmas nominais (SANTOS, 2015), de estratégias de hedging em Português como L3 (YUQI, 2015), de metáforas (PRESOTTO, 2016) e de hedgings em textos acadêmicos (SCHEPERS, 2016).

\section{Gêneros discursivos acadêmicos}

O ensino especializado de línguas muito se utiliza das noções levantadas pelos estudos discursivos sobre gêneros, o que já foi apontado por Marcuschi ao afirmar que "[...] muitos estudiosos de áreas diversas estão se interessando cada vez mais

por ele, tais como: [...] especialistas no Ensino de Inglês para Fins Específicos e professores de língua." (MARCUSCHI, 2008, p. 148-149); contudo, não há uma abordagem única que conduza à análise de gêneros discursivos.

Numa pesquisa conduzida por Araújo (2004), a pesquisadora encontrou nos seus dados que Swales, Bakhtin, Bronckart, Dolz e Schneuwly, Hallyday e Hassan, Fairclough, Kress, Pêcheux, Adam e Charaudeau figuram como as principais perspectivas teórico-metodológicas adotadas nos estudos levantados por ela em seu corpus de análise, com destaque para o primeiro. Outro fato interessante é que 
as combinações de perspectivas também estão presentes, como, por exemplo, a mais comum dentre elas, Swales e Bakhtin. Na seção sobre letramento acadêmico, retomaremos esses dados a fim de salientar a perspectiva swalesiana e suas contribuições para os estudos etnográficos que encerram questões de letramento como práticas sociais.

Neste momento, não pretendemos nos filiar a uma orientação somente; ao contrário, discorreremos conforme as vozes de autoridade desses autores se fizerem pertinentes para nos levarem a relacionar coerentemente seus pressupostos, a fim de caracterizar as atividades de linguagem estáveis na esfera acadêmica. Principiemos com a seguinte passagem conferida a Maingueneau:

Todo gênero de discurso implica que seus participantes dominem um certo uso da língua, caso desejem corresponder convenientemente às expectativas do gênero. Para cada tipo de atividade verbal há recursos linguísticos específicos: por exemplo, existe uma certa "linguagem administrativa" que mobiliza determinadas locuções prepositivas ("no que concerne a", "em virtude de" etc.), locuções verbais ("trazer ao conhecimento de"), certas construções de frases etc. (MAINGUENEAU, 2013, p. 75-76)

Logo, podemos sem problemas relacionar a citação acima com o proposto pelo PFA, pois a academia, como esfera discursiva, movimenta a linguagem e a estrutura de maneira muito típica, de tal forma que podemos denominá-la, nesse âmbito, de linguagem acadêmica, ou até mesmo um "academicês". Sendo a linguagem, de forma geral, caracterizada de acordo com cada atividade humana, ressaltamos que nem toda a atividade humana singulariza a linguagem nela empregada, ou seja “[...] não é todo gênero que implica necessariamente recursos linguísticos específicos. Existem várias atividades verbais para as quais, ao contrário, não há recursos próprios [...]." (MAINGUENEAU, 2013, p.77). Isso vai ao encontro da ideia bakhtiniana de que toda ação humana, mesmo que não demande recursos linguísticos específicos, se dá através de um texto que, por sua vez, é enunciado por meio de um gênero. (BAKHTIN, 2016; MARCUSCHI, 2008).

Podemos entender por esfera discursiva, ou domínio discursivo, uma determinada esfera de atividade humana, na qual existe um grupo de gêneros que compõem os textos que mais comumente nela circulam. Como explica Marcuschi, um domínio discursivo "[..] não abrange um gênero em particular, mas dá origem a vários deles [...]". (MARCSUCHI, 2008, p. 155). Essa variedade de gêneros que 
compõem uma esfera discursiva não existe por acaso, já que “[...] cada comunidade linguística possui o seu próprio sistema de registros [...] correspondentes à gama de atividades que seus membros normalmente desenvolvem.” (URE, 1982, p. 5 apud BIBER, 2006, p. 5). Em Bakhtin também encontramos ideia semelhante, quando o autor afirma que "[..] ]em cada campo existem e são empregados gêneros que correspondem às condições específicas de dado campo [...].” (BAKHTIN, 2016, p. 18).

A partir dessa breve conceituação de esfera ou domínio discursivo, é necessário determinar o que entendemos por gênero neste artigo. Tal definição se faz importante quando consideramos que "[..] a atividade cultural humana está sempre envolta em linguagem, e todos os nossos textos situam-se nessas vivências estabilizadas por gêneros." (MARCUSCHI, 2008, p. 163). De acordo com Miller (1984 apud Marcuschi, 2008), gêneros são formas de ação social, e podemos dizer, então, que a variedade de gêneros é determinada pela variedade de ações ou atividades humanas praticadas por meio da linguagem. Eles são, portanto, “[...] entidades comunicativas em que predominam os aspectos relativos a funções, propósitos, ações e conteúdos." (MARCUSCHI, 2008, p. 159, grifos do autor).

Pensando nos gêneros pertencentes ao domínio acadêmico, fica claro que saber a língua não determina saber produzir, ou até mesmo compreender, um determinado gênero. Isso se dá porque "[...] quando dominamos um gênero textual, não dominamos uma forma linguística e sim uma forma de realizar linguisticamente objetivos específicos em situações sociais particulares." (MARCUSCHI, 2008, p. 154). Bakhtin já postulava isso quando afirmou que "[..] muitas pessoas que dominam magnificamente uma língua sentem amiúde total impotência em alguns campos da comunicação, justo porque não dominam na prática as formas do gênero desses campos." (BAKHTIN, 2016, p. 41).

Ainda em relação ao código linguístico, Biber explica que a distinção entre os gêneros se faz não por meios linguísticos, mas “[...] por diferenças em propósito, em interatividade, em circunstâncias de produção, na relação entre os participantes, etc.” (BIBER, 2006, p. 7, tradução nossa). Isso não significa, obviamente, retirar da estrutura linguística a sua devida importância, apenas afirmar que, no que diz respeito ao entendimento do conceito de gênero, é preciso ir além das questões estritamente estruturais do código linguístico.

Retornando aos estudos de Bakhtin, vemos que o autor caracteriza os gêneros do discurso como "[...] tipos relativamente estáveis de enunciados". (BAKTIN, 
2016, p. 12). Tais enunciados possibilitam a representação de atividades humanas, pois "[...] cada campo dessa[s] atividade[s] [elabora] todo um repertório de gêneros do discurso, que cresce e se diferencia à medida que tal campo se desenvolve e ganha complexidade." (idem). É por isso que Marcuschi (2008) defende as atividades humanas e o contexto social como elementos imprescindíveis no estudo dos gêneros do discurso.

O próximo passo, portanto, é entendermos o que caracteriza aquilo que chamamos de competência genérica. Bakhtin afirma que "[..] ]em termos práticos, nós os empregamos [os gêneros] de forma segura e habilidosa, mas em termos teóricos podemos desconhecer inteiramente a sua existência." (BAKHTIN, 2016, p. 38). O autor ainda faz uma comparação entre a aquisição de nossa língua materna e a aquisição dos gêneros, afirmando que ambos nos são dados naturalmente. Contudo, acreditamos que tal afirmação seja verdadeira para os gêneros presentes no cotidiano, e não necessariamente para os mais especializados, os quais precisam ser ensinados. Por meio desse ensino, cremos ser possível aumentar a consciência do aluno para as características composicionais de um determinado gênero e promover, dessa forma, o desenvolvimento de uma competência genérica que permita a ele entender e produzir textos de uma determinada esfera discursiva. Como afirmou Bronckart "[...] a apropriação dos gêneros é um mecanismo fundamental de socialização, de inserção prática nas atividades comunicativas humanas" (BRONCKART, 1999, p. 103). É essa conscientização sobre as características dos textos da esfera acadêmica que cremos ser de extrema importância para alunos ingressos no ensino superior, pois é esse domínio dos gêneros que nos possibilita imprimir no discurso a nossa individualidade (BAKHTIN, 2016).

\section{Letramento acadêmico}

Dadas as questões discutidas na seção 2 sobre o ensino de EAP e de PFA, bem como as questões acerca dos gêneros acadêmicos naturais da esfera universitária, na seção 3, acreditamos ser propício retomarmos o que nesta foi apontado sobre a perspectiva swalesiana e suas contribuições para os estudos etnográficos, os quais estão muito relacionados com as questões de letramento como práticas sociais. Marcuschi, ao fazer um levantamento sobre algumas perspectivas em voga internacionalmente para o estudo dos gêneros, caracteriza a “[...] perspectiva 
sociorretórica de caráter etnográfico voltada para o ensino de segunda língua [...]" (2008, p. 153), como representada pelos estudos de John Swales e Vijay Bhatia. Esses autores seminais para os estudos de análise de gênero vêm reinterpretando seus pressupostos e metodologias de análise da língua em uso sob a forma de gêneros do discurso.

Segundo Araújo (2004), Swales e Askehave, mais especificamente, têm assumido recentemente uma posição interessante para os estudos discursivos ao proporem um caminho que parte da descrição da comunidade discursiva para chegar à descrição dos enunciados coletivamente construídos. Nas palavras de Araújo:

[...] Askehave e Swales (2001) propõem como procedimento alternativo e menos complicado começar-se com a identificação de uma comunidade discursiva, para a partir dela, estudar os valores, intenções e condições materiais da comunidade discursiva, as expectativas, o repertório de gêneros praticados, o redirecionamento dos gêneros, para só então caracterizar os gêneros que circulam em uma determinada comunidade. (ARAÚJO, 2004, p. 26).

Essa proposição dialoga com a de Street, em sua obra basilar Letramentos sociais, quando atesta que:

Uma das principais questões levantadas nessas discussões tem a ver com os modos como podemos mover o estudo do letramento para longe de generalizações idealizadas sobre a natureza da Linguagem e do Letramento e na direção de entendimentos mais concretos das práticas letradas em contextos sociais "reais". (STREET, 2014, p. 19).

Quando Street menciona discussões sobre os modos de ver o letramento, ele está criticando a concepção de letramento, adotada por alguns pesquisadores, como algo neutro e estanque. Essa visão não coincide com a natureza social do letramento, nem com o "[...] caráter múltiplo das práticas letradas." (STREET, 2014, p. 18).

A crítica de Street a essa perspectiva é muito contundente e reiteradamente ele lembra que "[..] a abordagem das práticas letradas [...] representa uma visão particular da noção de "língua real"- isto é, a leitura e a escrita são inseridas aqui em práticas sociais e linguísticas reais que lhe conferem significado [...]". (STREET, 2014, p. 19). Continuando, afirma que "[..] o foco no contexto, portanto, 
é o que torna "reais" as Práticas Letradas aqui descritas [no livro]". (2014, p. 19). Essa interpretação, de certa forma, se aproxima do caráter etnográfico através do qual Swales se orienta.

Como acima referido, então, práticas sociais constituem letramentos sociais, o que não é diferente do ocorrido dentro do mundo acadêmico. Conforme vimos ao longo do texto, demonstrado através dos argumentos de autoridade e conceitos por eles trazidos, a falta de competência genérica pode trazer frustrações e falhas na comunicação dos sujeitos inseridos num contexto qualquer, ao mesmo tempo em que o ensino não focalizado, seja para fins específicos, seja para fins acadêmicos, também não contribui para a construção de um ser letrado. E o que vem a ser, nesse caso, um letramento acadêmico?

Ser academicamente letrado significa que um aprendiz tem um repertório de estratégias efetivas para compreender e usar as diferentes linguagens, especializadas e contextualizadas, no domínio acadêmico. Ainda, indica os papéis sociais (pelo menos desejáveis) de alunos e professores, as finalidades de os alunos estarem neste domínio e as relações estabelecidas com o conhecimento e com o saber. (FISCHER, 2008, p. 180-181).

Portanto, defendemos que, aliada à análise de gêneros discursivos acadêmicos, a metodologia de ensino de PFA, nos moldes do consagrado EAP, pode, em muito, contribuir para se criar uma tradição de letramento acadêmico que propicie ao estudante uma experiência mais significativa, não somente na sua esfera acadêmica, mas também no domínio discursivo do qual irá participar, quando egresso da universidade e apto para atuar na sua profissão. Abaixo, na Figura 2, está condensado um aporte teórico-metodológico que julgamos suficientemente abrangente para abarcar fenômenos culturais e linguísticos dentro dos limites da academia: 
Figura 2 - Triângulo Etnográfico-Discursivo

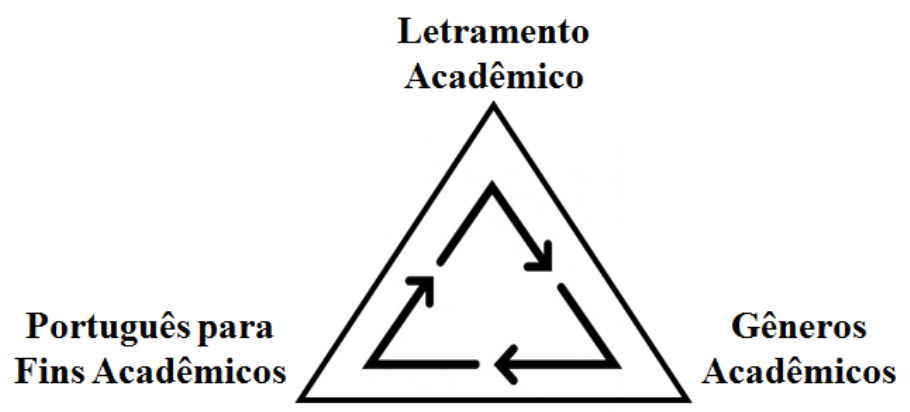

Fonte: Elaboração dos autores, 2017.

Fischer (2008) aplica em seus estudos a ideia de que o letramento é uma prática social. Em um de seus trabalhos, a autora contrasta alunos ingressantes e formandos do curso de Letras em uma universidade portuguesa, no intuito de identificar as práticas de letramento que fizeram parte da formação desses estudantes, considerando, inclusive, experiências prévias à inserção na graduação. Seu objetivo é identificar de que forma a interação no meio acadêmico impactou no uso da linguagem e na formação docente dos sujeitos. A autora também reconhece a complexidade envolvida na conceituação de "letramento", como podemos ver no trecho a seguir, em que ela recorre a Barton e Hamilton para justificar a dificuldade da tarefa:

Explicar e definir letramento não constitui tarefa fácil, se este for compreendido como um fenômeno complexo, por indicar a orientação e a constituição de pessoas marcadas pela história, por aspectos sociais, políticos, econômicos e culturais. O letramento, na perspectiva de uma teoria social, representa um conjunto de práticas sociais capazes de serem realizadas pelas pessoas [...]. (BARTON; HAMILTON, 2000 apud FISCHER, 2008, p. 178)

O posicionamento de Fischer (2008) é provavelmente influenciado pela obra de Street, que também vê o letramento como uma prática social. Street entende o aprendizado da escrita como uma questão relacionada à identidade do aluno, e não apenas à aquisição de habilidades específicas, já que devemos considerar também o contexto em que tais práticas acadêmicas ocorrem e as relações de poder envolvidas. É preciso que o currículo envolva uma diversidade de gêneros 
referentes à disciplina de estudo, a fim de que sejam dadas aos alunos diferentes oportunidades de prática comunicativa, para que ele possa desenvolver um cabedal de práticas linguísticas associadas a diferentes contextos (STREET, 2010). Cremos ser essa a melhor maneira de auxiliar o aluno a participar efetivamente do ambiente acadêmico que o rodeia.

\section{Considerações finais}

É interessante notar a ampla gama de estudos de gênero, principalmente quando pensamos em gêneros que compõem aquilo que, neste artigo, entendemos como pertencentes à esfera acadêmica. Tais estudos já têm uma longa trajetória em língua inglesa e, no Brasil, começam também a despontar trabalhos que buscam uma abordagem mais ampla, que vá além da ideia de gêneros como "caixas" nas quais os textos precisam se enquadrar para que possam ser classificados. Essa abordagem mais ampla de estudos de gênero em língua portuguesa, por sua vez, vem acompanhando as discussões acerca do desenvolvimento do PFA, na tentativa de definir melhores maneiras de ensinar português focando não apenas as questões linguísticas, mas colocando a língua em contexto para produzir uma determinada atividade.

Iniciativas que consideram essas questões, por exemplo, são os centros de escrita acadêmica encontrados em algumas instituições de ensino superior no exterior. Enquanto em países norte-americanos e europeus podemos citar os centros das universidades de Cambridge ${ }^{4}$, Emory ${ }^{5}$ e Notre Dame ${ }^{6}$, já contando com anos de pesquisa e ensino, no Brasil, até o presente momento, temos somente como exemplo o primeiro centro de escrita acadêmica em língua inglesa ${ }^{7}$, o "Centro de Assessoria de Publicação Acadêmica $\left(\mathrm{CAPA}^{8}\right)^{)}$, da Universidade Federal do Paraná (UFPR), fundado em 2016.

Dada a complexidade do contexto sócio histórico do sistema educacional brasileiro, seria extremamente injusto deixar sequer subentendido neste trabalho que creditamos aos professores de língua portuguesa a pouca prática dos

4 Para mais informações, consulte: https://goo.gl/9LjBf0.

5 Para mais informações, consulte: https://goo.gl/JZmVaW.

6 Para mais informações, consulte: http://writingcenter.nd.edu/.

7 Disponível em: https://goo.gl/7jwQKn. Acesso em: 27 abr. 2017.

8 Para mais informações, consulte: http://www.capa.ufpr.br . 
alunos ingressos nos cursos de graduação com os gêneros da esfera acadêmica. Entendemos claramente que o ensino desses gêneros não necessariamente faz parte daquilo que se espera que os professores trabalhem com seus alunos nas escolas. Acreditamos, contudo, que o estudo dos gêneros do discurso, que tem vasta menção em documentos oficiais como os Parâmetros Curriculares Nacionais (PCN) e os Referenciais Curriculares do Rio Grande do Sul, serve como aporte teórico tanto para o ensino fundamental e médio quanto para o trabalho de letramento acadêmico de alunos ingressantes em cursos universitários, e que deve ser desenvolvido e incentivado por professores de todas as disciplinas.

Vemos na ideia de competência genérica uma das chaves para inserção plena desse estudante no meio acadêmico, mesmo que sua intenção não seja seguir a carreira acadêmica após o término da graduação. Para que sua trajetória profissional possa se desenvolver de maneira efetiva, já no curso universitário, esse aluno precisa entender e produzir textos, orais e escritos, que o legitimem e o ajudem a fazer parte do contexto em que está inserido. Esta seria, portanto, de acordo com nossa perspectiva, uma das formas de empoderar o aluno para que participe plenamente da esfera discursiva acadêmica, e das outras nas quais venha a participar.

Afora essas questões, é imprescindível termos como reflexão constante que os letramentos sociais aos quais somos expostos não constituem práticas somente de textos orais e escritos, mas constituem práticas sociais a partir das quais produzimos textos. Street (2010) revela que se encontram questões muito mais profundas sobre as práticas pedagógicas de letramento:

Aliado a isso está o trabalho em Análise Crítica do Discurso, Linguística Sistêmica e Antropologia Cultural que tem abordado a escrita do aluno como constitutiva e contestável ao invés de abordar como habilidades ou déficits. Há uma literatura crescente baseada nessa abordagem, que sugere que uma explicação para problemas de escrita do aluno pode ser as lacunas entre as expectativas da equipe acadêmica e as interpretações do aluno sobre o que está envolvido na sua escrita [...]. (STREET, 2010, p. 349, tradução nossa)

Como o autor menciona, outra possível causa desse distanciamento professoraluno seria a lacuna entre as expectativas do corpo docente e o entendimento do aluno sobre o que está em jogo no seu labor científico, o qual, no fim, provavelmente, venha a se moldar sob a forma de um texto oral ou escrito. Outrossim, vemos 
que não é somente através do ensino de escrita de textos acadêmicos (o mesmo vale para os textos orais) que teremos condições de abordar o fenômeno sociocomunicativo em jogo, pois questões etnográficas devem estar em mente quando se pensa em ensinar algo a uma dada comunidade. Entender como ela funciona também é um trabalho de profunda base antropológica. Ao longo do texto, buscamos criar condições de reafirmar e defender o título que encabeça o presente artigo, pois, para o intervalo que se põe entre a escola e a universidade, é dada, como justificativa, mais do que uma questão genérica tão somente, e sim uma questão de letramento social, o qual se preocupa com a constituição crítica do pensamento de sujeitos transformadores das suas vidas.

Um próximo passo metodológico pertinente para a discussão teórica até aqui desenvolvida seria o levantamento mais apurado dos gêneros presentes na escola e na universidade, bem como das práticas de letramento oferecidas e das concepções de linguagem dos professores nessas duas esferas. Cremos que essa etapa caracterizaria a realidade que se estabelece nesse intervalo, para então desenvolver práticas consistentes de letramento numa base etnográfica.

\title{
The gap between School and University: beyond a genre analysis
}

\begin{abstract}
This article aims at bringing to the agenda of discussions about literacy in the university the gap between teaching and learning of school genres and academic genres. Our concern results from incoming students in higher education institutions who did not have a school experience with a view to a social literacy practice. From the proposed theme, we reflect on how the theory of discourse genres, as well as its applicability, helps in the development of the academic literacy of these undergraduate students. The proficiency, or insertion, in the academic discourse sphere is closely related to the generic competence that students must possess to ensure their communication in order to reach their status as discursive and transforming individuals. Therefore, we argue that, together with the analysis of academic discourse genres, the teaching methodology of Portuguese for Academic Purposes, in the form of the English for Academic Purposes, can greatly contribute to create a tradition of academic literacy that provides students with a more meaningful experience not only in their academic sphere but also in the discursive domain that they participate in, once graduated from college and able to act in their professions.
\end{abstract}

Keywords: Portuguese for academic purposes. Academic genre. Academic literacy. 
Referências

ARAÚJO, Antonia Dilamar. Gêneros textuais acadêmicos: reflexões sobre metodologias de investigação. Revista de Letras, v. 1/2, n. 26, p. 21-27, 2004.

BAKHTIN, Mikhail. Os gêneros do discurso. Org., trad., posfácio e notas de Paulo Bezerra. Notas da edição russa de Serguei Botcharov. Editora 34: Rio de Janeiro, 2016.

BIBER, Douglas. University Language: a corpus-based study of spoken and written registers. Philadelphia: John Benjamins, 2006.

BRONCKART, Jean Paul. Atividades de linguagem, textos e discursos. Por um interacionismo sócio-discursivo. Tradução de Anna Rachel Machado e P. Cunha. EDUC: São Paulo, 1999.

FISCHER, Adriana. Letramento acadêmico: uma perspectiva portuguesa. Acta Scientiarum. Language and Culture, Maringá, v. 30, n. 2, p. 177-187, 2008.

FLOWERDEW, John; PEACOCK, Matthew. Research perspectives on English for Academic Purposes. Cambridge: Cambridge University Press, 2001.

HYLAND, Ken. English for academic purposes: an advanced resource book. Routledge: Londres/Nova York, 2006.

JORDAN, R. R. English for academic purposes: a guide and resource book for teachers. Cambridge: Cambridge University Press, 1997.

MAINGUENEAU, Dominique. Análise de textos de comunicação. Tradução de Maria C. Souza-e-Silva e Décio Rocha. 6. ed., Cortez: São Paulo, 2013.

MARCUSCHI, Luiz Antônio. Produção textual, análise de gêneros e compreensão. Parábola Editorial: São Paulo, 2008.

MOLSING, Karina V.; PERNA, Cristina. The pronominal use of -se in Brazilian Portuguese academic writing. No prelo.

MORO, Beatriz Ilibio. Advérbios de posicionamento em textos escritos de português acadêmico. 2014. Dissertação (Mestrado em Letras) - Programa de Pós-Graduação em Letras, Pontifícia Universidade Católica do Rio Grande do Sul, Porto Alegre, 2014.

PRESOTTO, Letícia. Metáforas no português acadêmico. 2016. Dissertação (Mestrado em Letras) - Programa de Pós-Graduação em Letras, Pontifícia Universidade Católica do Rio Grande do Sul, Porto Alegre, 2016. 
SANTOS, Sheila Nunes dos. Uma análise dos substantivos como marcadores de posicionamento em artigos acadêmicos em língua portuguesa. 2015. Tese (Doutorado em Letras) - Programa de Pós-Graduação em Letras, Pontifícia Universidade Católica do Rio Grande do Sul, Porto Alegre, 2015.

SCHEPERS, Bruna Milano. Transferência de estratégias de hedging: um estudo contrastivo entre o português brasileiro e o inglês. 2016. Dissertação (Mestrado em Letras) - Programa de Pós-Graduação em Letras, Pontifícia Universidade Católica do Rio Grande do Sul, Porto Alegre, 2016.

STREET, Brian. Letramentos sociais: abordagens críticas do letramento no desenvolvimento, na etnografia e na educação. Tradução de Marcos Bagno. Parábola Editorial, São Paulo, 2014.

STREET, Brian. Academic Literacies approaches to Genre? Revista Brasileira de Linguística Aplicada, Belo Horizonte, v. 10, n. 2, p. 347-361, 2010.

YUQI, Sun. Hedgings em textos acadêmicos: uma perspectiva de aquisição de L3. 2015. Tese (Doutorado em Letras) - Programa de Pós-Graduação em Letras, Pontifícia Universidade Católica do Rio Grande do Sul, Porto Alegre, 2015. 